\title{
Article
}

\section{Knud Rasmussen Glacier Status Analysis Based on Historical Data and Moving Detection Using RPAS}

\author{
Karel Pavelka *(D), Jaroslav Šedina and Karel Pavelka, Jr.
}

Faculty of Civil Engineering, Czech Technical University in Prague, Thakurova 7, 16629 Prague, Czech Republic; Jaroslav.sedina@gmail.com (J.Š.); karel.pavelka@hotmail.com (K.P.J.)

* Correspondence: pavelka@fsv.cvut.cz; Tel.: +420-608-211-360

Citation: Pavelka, K.; Šedina, J.; Pavelka, K., Jr. Knud Rasmussen Glacier Status Analysis Based on Historical Data and Moving Detection Using RPAS. Appl. Sci. 2021, 11, 754. https://doi.org/10.3390/app11020754

Received: 30 November 2020

Accepted: 12 January 2021

Published: 14 January 2021

Publisher's Note: MDPI stays neutral with regard to jurisdictional clai$\mathrm{ms}$ in published maps and institutional affiliations.

Copyright: (C) 2021 by the authors. Licensee MDPI, Basel, Switzerland. This article is an open access article distributed under the terms and conditions of the Creative Commons Attribution (CC BY) license (https:// creativecommons.org/licenses/by/ $4.0 /)$.

\begin{abstract}
This article discusses partial results of an international scientific expedition to Greenland that researched the geography, geodesy, botany, and glaciology of the area. The results here focus on the photogrammetrical results obtained with the eBee drone in the eastern part of Greenland at the front of the Knud Rasmussen Glacier and the use of archive image data for monitoring the condition of this glacier. In these short-term visits to the site, the possibility of using a drone is discussed and the results show not only the flow speed of the glacier but also the shape and structure from a height of up to $200 \mathrm{~m}$. From two overflights near the glacier front at different times, it was possible to obtain the speed of the glacier flow and the distribution of velocities in the glacier stream. The technology uses a comparison of two point clouds derived from a set of aerial photos taken with the eBee drone, and calculating the M3C2 (Multiscale Model-to-Model Cloud Comparison) distances with CloudCompare software. The results correlate with other measurement methods like accurate and long-term measurement with Global Navigation Satellite System (GNSS), satellite radar, or ground geodetical technology. The resulting speed from the drone data reached in the middle part of the glacier, was approximately $12-15 \mathrm{~m}$ per day. The second part of the paper focuses on the analysis of modern satellite images of the Knud Rasmussen Glacier from Google Earth (Landsat series 1984-2016) and Sentinel 2a, and a comparison with historical aerial images from 1932 to 1933. Historical images were processed photogrammetrically into a three-dimensional (3D) model. Finally, orthogonalized image data from three systems (drone photos, historical aerial photos, and satellite data) were compared in the ArcGIS software. This allows us to analyze glacier changes over time in the time span from 1932 to 2020, with the caveat that from 1933 to 1983 we did not have data at our disposal. The result shows that more significant changes in the area of this glacier occurred after 2011. The main aim of this article is to research the use of photogrammetric methods for monitoring the condition and parameters of glaciers based on non-traditional technology, such as drones or new processing of historical photos.
\end{abstract}

Keywords: photogrammetry; RPAS; CloudCompare; Bee; Greenland; Knud Rasmussen Glacier

\section{Introduction}

I would like to dedicate this article in memoriam to my friend, scientist, and real man, Professor Wilfried Korth (Figure 1), who died tragically in spring 2019, just before his last planned expedition to Greenland (KP).

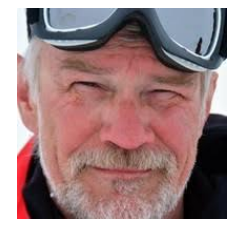

Figure 1. Professor Wilfried Korth († 2019). 
The gradual melting of glaciers has been monitored for a long time. Since the 1980s, ice has been declining more than it is replenished in winter. Winters are milder and summers longer and warmer. The ice that disappears will not be restored. Nowadays, six times more ice has been disappearing from Greenland than in the 1980s [1].

The Greenland cap is a vast mass of ice covering 1.7 million square $\mathrm{km}$, which represents about $80 \%$ of Greenland's surface. It is the second largest glaciated area in the world; the first is the Antarctic cap. Its thickness is usually more than $2 \mathrm{~km}$ and sometimes exceeds $3 \mathrm{~km}$ [2]. The weight of the glacier has compressed the central part of Greenland, bringing the rocky bedrock below it to about sea level, while the mountain range surrounds the glacier almost along its entire edge. This is detectable by the deformation of the Earth's gravity field. If the entire Greenland cap melted, the level of the world's oceans would rise by about $7 \mathrm{~m}$. Due to the long-term melting of the glacier, the compressed rock is gradually rising on the outskirts of Greenland. According to scientific studies, the Greenland coast rises by $2.5 \mathrm{~cm}$ per year [3-5]. However, it is also scientifically confirmed that some parts of the glacier are even increasing. This information indicates that the condition of the Greenland cap must continue to be carefully studied. Today, scientific satellites in particular are contributing to this [6].

The mapping of Greenland began as early as the 15th century, when parts of the coast were mapped. However, systematic mapping became possible only in the 20th century, using aerial photogrammetry and later satellites. A significant achievement was the Danish geodetic expedition from 1931 to 1934. Many aerial photographs were taken using three Heinkel seaplanes. These photographs are the perfect source for monitoring the condition of Greenlandic glaciers (Figure 2).

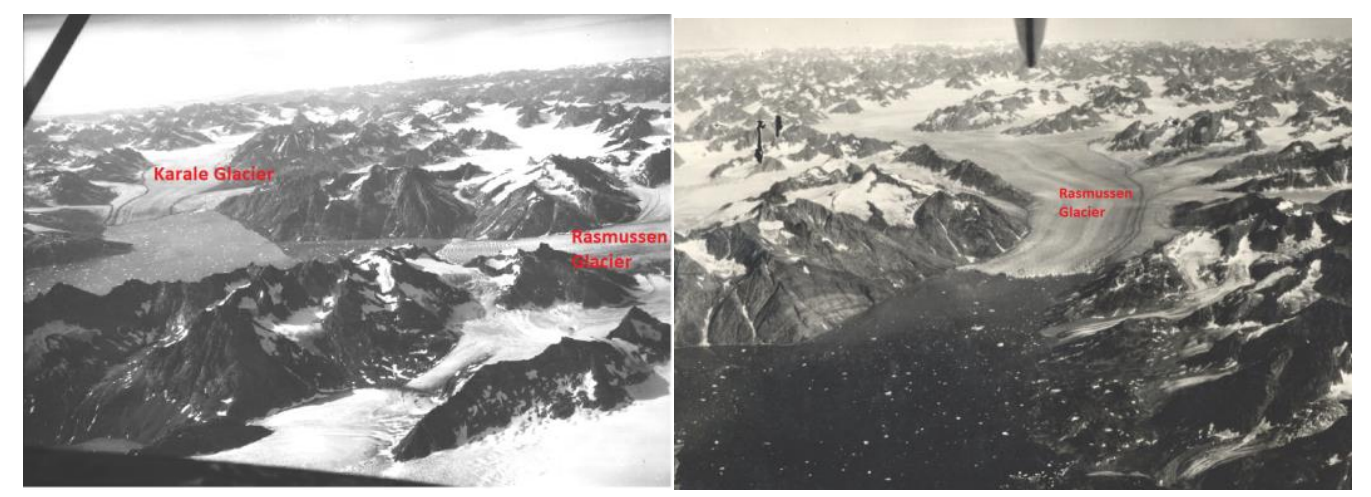

Figure 2. The Knud Rasmussen Glacier in a photo from the Danish Greenland expedition (the seventh Thule Expedition 1932-1933); (photo: the Arctic Institute, https:/ / arktiskinstitut.dk).

During the seventh Thule Expedition, a systematic survey of the southeast coast of Greenland was carried out from 1932 to 1933. Nowadays, at the Natural History Museum of Denmark, there is a long-term project called "AirBase". It is a database which has a quarter of a million aerial photos recorded by Danish survey agencies in the period from 1930 to the 1980s. This is a unique source of information about glaciers $[7,8]$.

\section{Project Aims}

Based on the scope of this Special Issue call "Analyses in Geomatics: Processing Spatial Data on History and Today", we focused on the processing of spatial and historical data. Two goals have been defined as follows:

\subsection{Measuring the Glacier Flow Speed}

In this project, the primary aim was to calculate the speed of movement and its distribution of the glacier based on two drone overflights performed at different times. This method compares two points clouds derived from photo sets to get these parameters. 


\subsection{Detection of Long-Term Changes in the Extent of the Glacier}

Another goal was to detect changes in the extent of the glacier based on the analysis of historical image data. The on-site measurement in 2019 was compared with historical image data. There are freely available data from satellites on the web, accessed via Google Earth, new free satellite data from the Copernicus system, and we also managed to get historical photographic aerial data from the Danish archive. The data can be processed in geographic information system (GIS), and the glacier extent changes over time can be modelled.

\section{Study Area}

Based on the collaboration between the Beuth Hochschule für Technik Berlin, TU Cottbus, and the Czech Technical University in Prague, Faculty of Civil Engineering, and the successfully first joint expedition in 2015, a second expedition was carried out in 2019 [9]. This expedition with the research ship Dagmar Aaen led by Mr. Arved Fuchs was planned along the east coast of Greenland. Our part in the expedition was photogrammetry.

Our goals of the photogrammetrical works during the Greenland expedition 2019 was to create a detailed map of the abandoned U.S. military air base Bluei East II and research the movement of the Knud Rasmussen Glaciers using the drone. Both sites are located within a few days of sailing from Kulusuk/Tasiilaq (Figure 3). This research is a followup to a number of projects focused on documenting glaciers using drones and detecting changes using point clouds [10-12]. As a study area analyzed in this article, the famous Knud Rasmussen Glacier was selected. It is a well-known formation and can be reached by sea (Figures 3 and 4 ). The choice of this glacier was given mainly by the possibility to obtain archival aerial data photographed during the Danish Greenland expedition in 1930s.

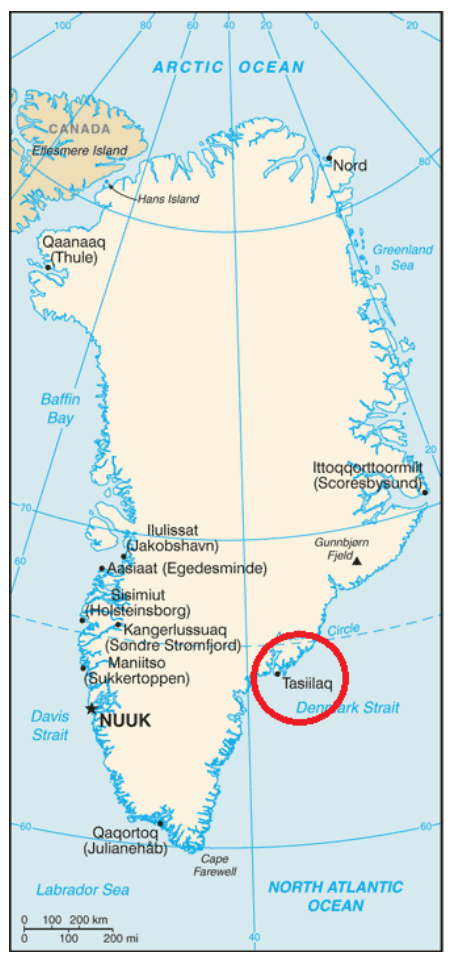

(a)

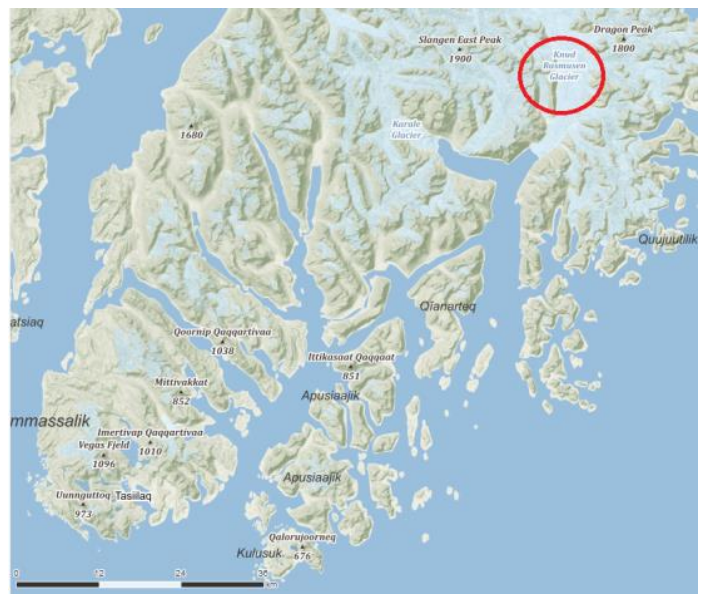

(b)

Figure 3. (a) Map of Greenland (http:/ /www.getamap.net/maps/greenland_\%5B_denmark_\%5 D/ostgronland/_knud_rasmussen_glacier/) and (b) the Knud Rasmussen Glacier (66.0817028N, 36.3402919W), (http://www.mapy.cz). 


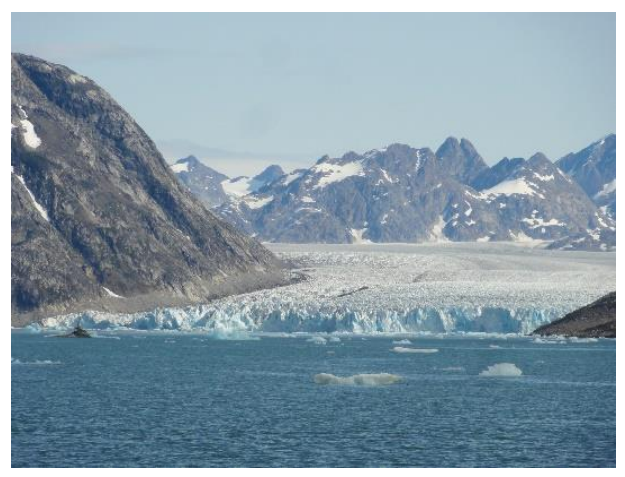

Figure 4. Knud Rasmussen Glacier; it appears to be a small glacier, but its width is over $2 \mathrm{~km}$.

\section{Used Instruments}

Remotely piloted aircraft system (RPAS) is a less used but correct acronym for a drone [13]. The eBee drone, senseFly, from Switzerland, was used in this case for different reasons. (1) It is light, made from Styrofoam, easy to use, takes off by hand, and lands without any special landing pad, (2) it is easy to transport (in a padded backpack), can be divided into several parts for transport, is electrically powered, and uses small batteries, (3) it has a relatively long time of flight up to $40 \mathrm{~min}$ and altitude access of hundreds of $\mathrm{m}$, because it is a winged drone, and (4) it flies with full autonomy based on GNSS (Global Navigation Satellite System) and IMU (Inertial Measurement Unit) devices and the flight plan, and has changeable cameras (Figures 5 and 6). However, the drone weighs less than one kilogram and the flight can be affected by gusts of wind, and furthermore, cameras used in this type is low-cost only. Unfortunately, the type used was not a GNSS RTK (Real Time Kinematic) system, which allows precise georeferencing of outputs without geodetically measured ground control points (GCP).

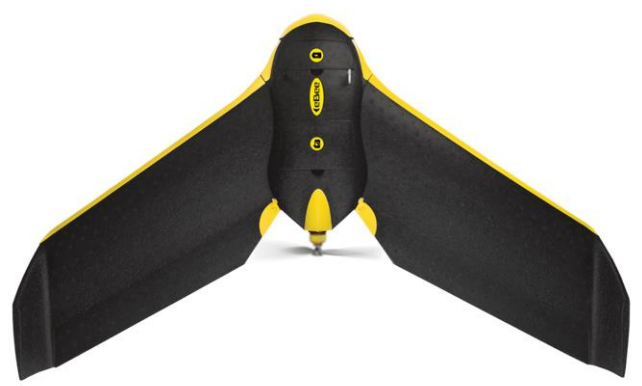

Figure 5. The Remotely piloted aircraft system (RPAS) eBee.

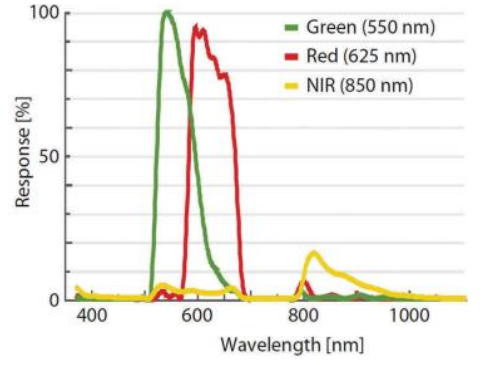

(a)

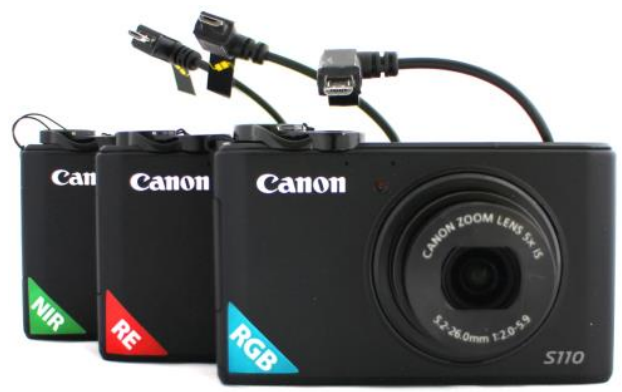

(b)

Figure 6. (a) Spectral response of the Canon PowerShot ELPH 110 HS (NIR) and (b) the changeable cameras for the eBee drone: near-infrared (NIR), red-edge (RE), and red-green-blue (RGB). The camera has a 1/1.7" back-illuminated CMOS (Complementary metal-oxide-semiconductor) sensor, image size 12.1 MPix, camera weight $153 \mathrm{~g}$ excl. battery. 


\section{Data Capturing}

Image data acquisition is described here. Data from RPAS were obtained directly at the research site, archival satellite data were obtained from free sources on the web and we also got unique historical aerial photos thanks to the kind approach of the Danish side.

\subsection{RPAS Data Capturing}

Before the flights, flight planning is necessary. The eMotion software is used with the eBee system running on a notebook. This software uses a common GNSS device for navigation. During the flight planning in this software, satellite images from ordinary free web sources (Google, Microsoft, Nokia, and others) are used as a map background. Unfortunately, in Greenland, actual satellite data from these sources was unavailable, and it was not possible to precisely define the exact parameters and destination of the drone flight. This proved to be a problem with flight planning $[10,13,14]$. The front of the glacier was hundreds of $m$ away from the latest satellite images, so the flight plan had to be estimated on-site (Figure 7).

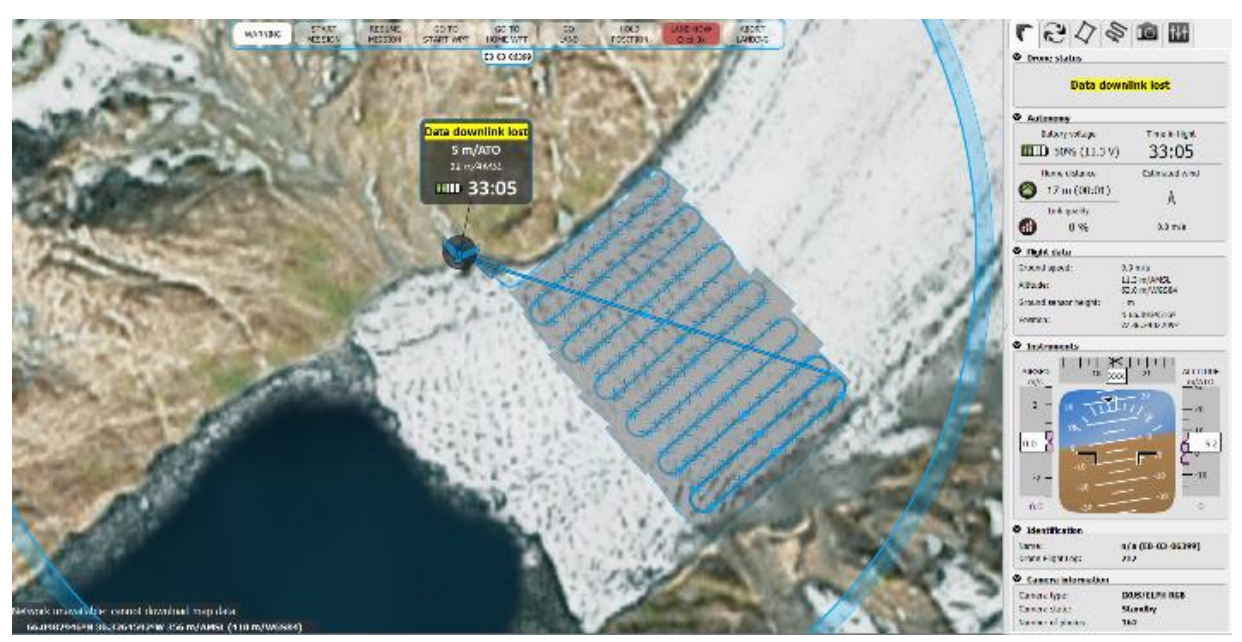

Figure 7. Flight no.1, senseFly eMotion 2 software; the map background from Google Earth was out of date (2016). The flight plan was prepared at the university before expedition, but the actual position of the glacier front was elsewhere. There was no internet on site, the flight plan had to be estimated and changed at the measurement site.

One single day was set aside for the measurement, and there was not more time. Two changeable cameras were at the drone's disposal during the expedition. Unfortunately, due to a malfunction in the RGB camera, only the NIR (near-infrared) camera was used. As it turned out, the NIR images were more suitable for capturing ice than an RGB camera, because the glacier ice is off-white to light blue, which is not perfect for the image correlation used for image processing. Using the drone eBee, two overflights of the same area were performed on 16 July 2019 with a time span of about four hours. During the first flight, a total of 162 NIR images were taken (Figure 8). During the second flight, 170 NIR images were recorded. During the first flight, the signal was lost due to a very high rock cliff near the last flight line; the drone emergency system interrupted the flight and returned it to the take-off point. For this reason, the number of images is not the same for both flights; however, the loss of eight images did not affect the project. The last flight line was not fully completed; there was no time to repeat the flight and therefore the second flight was slightly modified. 


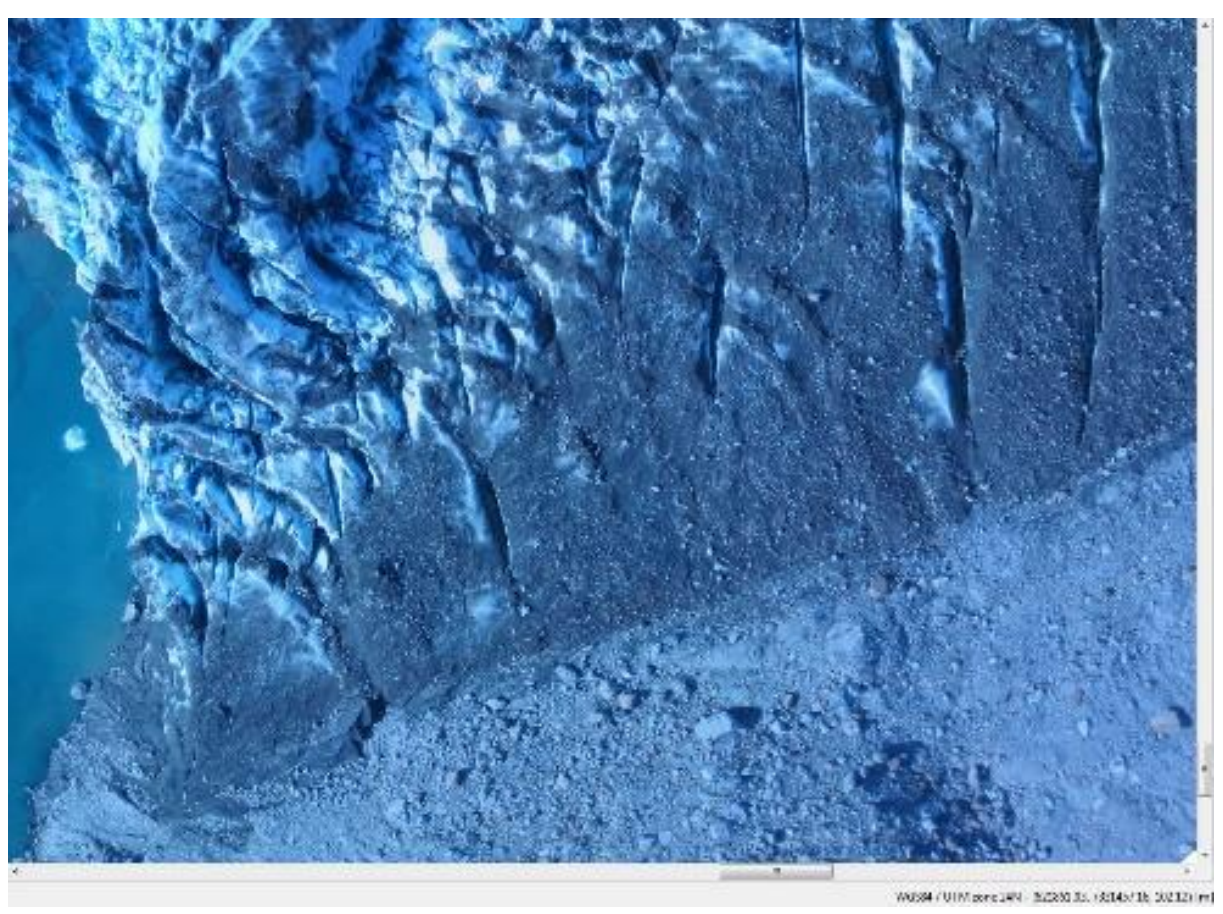

Figure 8. A typical photo using NIR camera Canon PowerShot ELPH 110 HS (NIR).

The flight time took approximately $35 \mathrm{~min}$ at an altitude of $180 \mathrm{~m}$. Due to the smaller capacity of the batteries in the frost, we did not choose a lower flight or a longer flight. Another problem was the high rocks on both sides of the glacier.

The aim was to record both shores of the moraine (see Figure 7), which could not change in a few hours, unlike the movement of the glacier, which was supposed to be the largest somewhere in the middle.

\subsection{Historical Image Data}

In this part of the project, the aim was to show the possibility of using different types of image data for long-term monitoring of the state of the glacier and especially the new processing of historical aerial photographs into an orthophoto, which is compatible with modern data.

There is aerial and satellite data available. Regular satellite imagery has been for civilian use since the 1980s. Historically, this is mainly data from Landsat satellites. Newer satellite data can be found from the Copernicus system. Here we were interested in freely available data only. These are available on Google Earth or on similar map servers, where they are already processed into a map form and are of lower quality, which does not matter in this case, because only the changing shape of the glacier front was analyzed. Professional original satellite data acquired from public funds are today on data archive accessible via access hub like http:/ / scihub.copernicus.eu or https: / / earthexplorer.usgs. gov /. Aerial image data are often used for business, mainly for mapping and typically are not free available on web. Really old historical aerial data can be found in museum data archives. The Knud Rasmussen Glacier area was photographed during the Danish Greenland expedition by the seventh Thule Expedition from 1932 to 1933. It was thus possible to study the condition of the glacier now and compare it with its condition almost ninety years ago. Thank to Anders Anker Bjørk from the Department of Geoscience and Natural Resource Management, University of Copenhagen, we got a set of historical aerial images from the Danish Greenland expedition in the 1930s (Figure 9). 


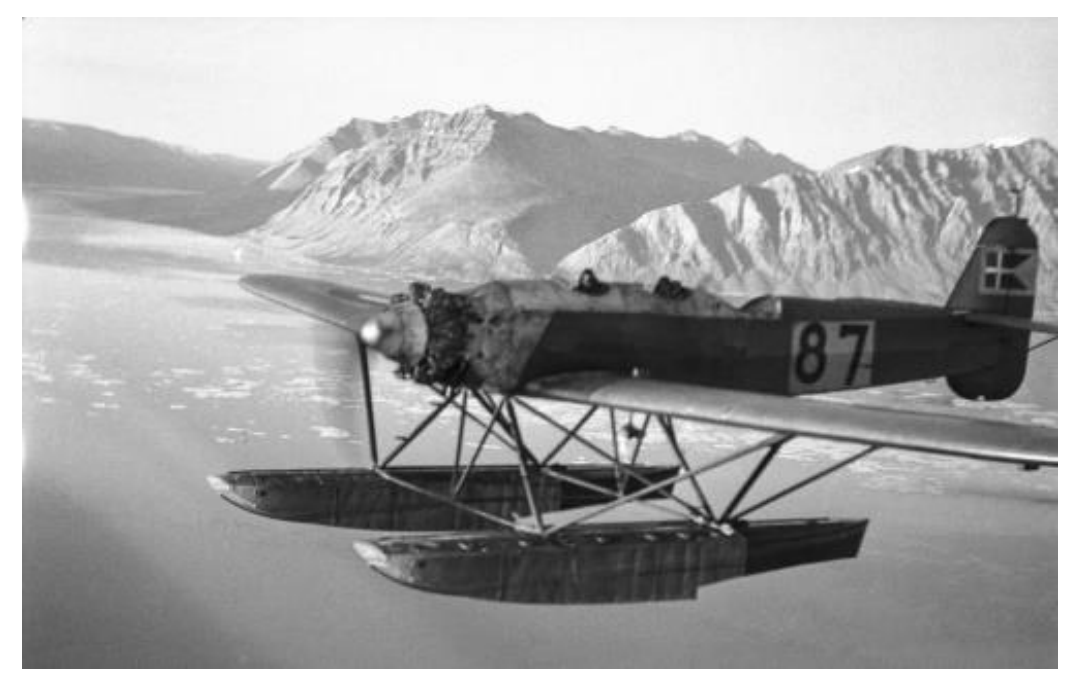

Figure 9. The Heinkel seaplane with open cockpit for three persons (pilot, radio-operator, and photographer in the back (photo: the Arctic Institute, https://arktiskinstitut.dk). The taking of the photos was carried out from a height of up to $4500 \mathrm{~m}$ at a temperature of -40 degrees Celsius frequently. Nowadays, these conditions are hardly imaginable.

\section{Data Processing}

As was written, in this project two types of data were used. First, aerial images taken from a low altitude by the RPAS eBee on-site, and second, satellite and aerial archive data.

\subsection{RPAS Data Processing}

The modern digital aerial photogrammetry serves the classic outputs in the form of orthophoto and digital surface model (DSM) based on a point cloud that was calculated using image correlation technology, called image-based modelling and rendering (IBMR) or structure from motion (SfM). This technology uses a set of highly overlapped photos. Based on computing of a sparse point cloud from photographs, the internal and external parameters of the chosen camera can be computed. After this, a dense point cloud is calculated, which is similar to the point cloud measured directly using laser scanners.

\subsubsection{Creating of Point Clouds}

The data could only be processed in a laboratory at the university and not directly during the expedition. The calculation was performed in Pix4D and later in Metashape software; both software work with parameters from GNSS and IMU devices on board the eBee drone. Metashape software provides a more detailed point cloud, which is why these outputs were used in the next processing.

A computing of the glacier shift measured from two points clouds is non-trivial, because of the nonlinear movement of the glacier. The glacier moves slowly at the edges and fastest in the middle. The difference or the discrepancies between two points clouds is usually calculated in CloudCompare software.

By the computing in Metashape software, 74,416 tie points were found in the first set of images for a sparse point cloud. In the second set of images, the number of tie points was 92,693. After the depth map was created, 221,341,562 points for a dense point cloud were created for the flight and 231,635,556 for the second flight. Both point clouds were exported without modifying their original coordinate systems. It means that the second point cloud was not transformed into the coordinate system of the first point cloud.

A point cloud, orthophoto, and DSM was made from each photo flight and exported to the ArcGIS software (Figures 10 and 11). 


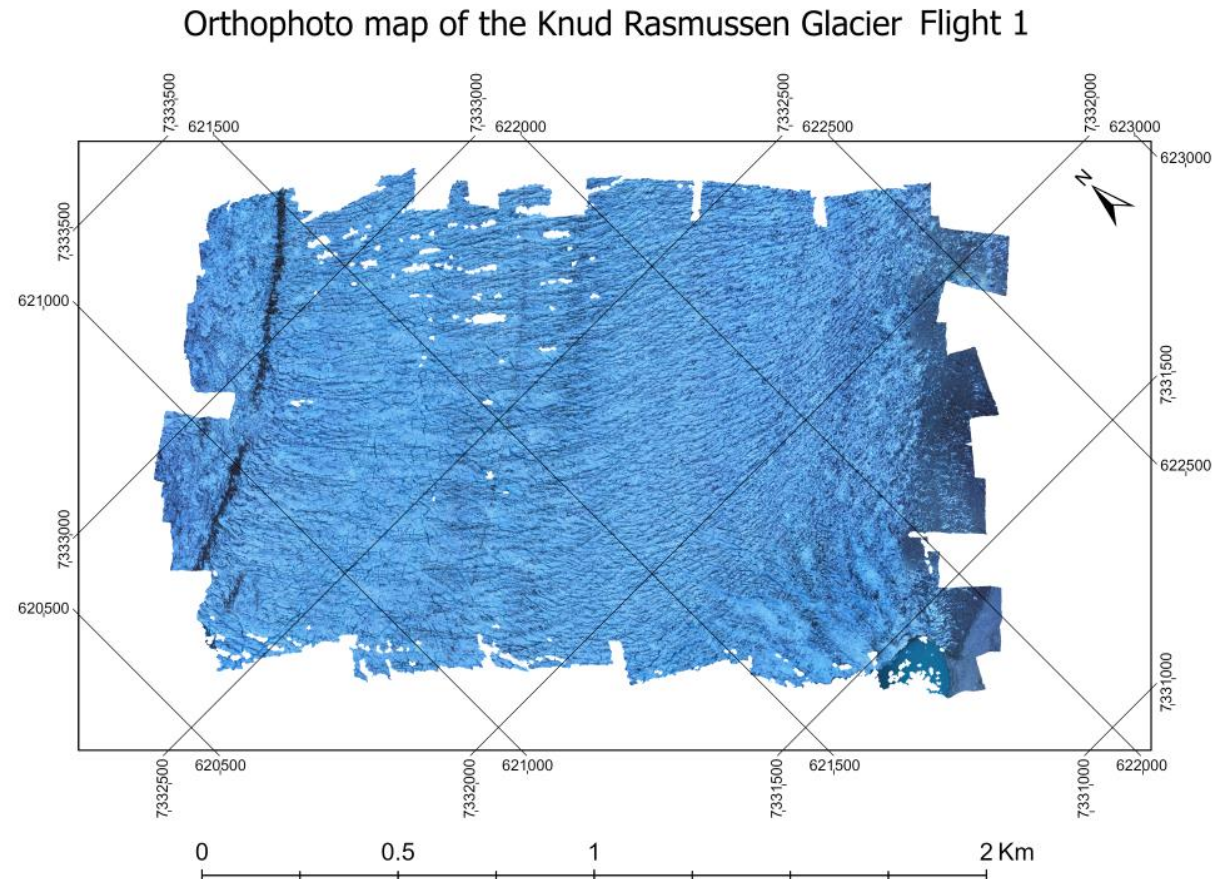

Orthophoto map of the Knud Rasmussen Glacier Flight 2

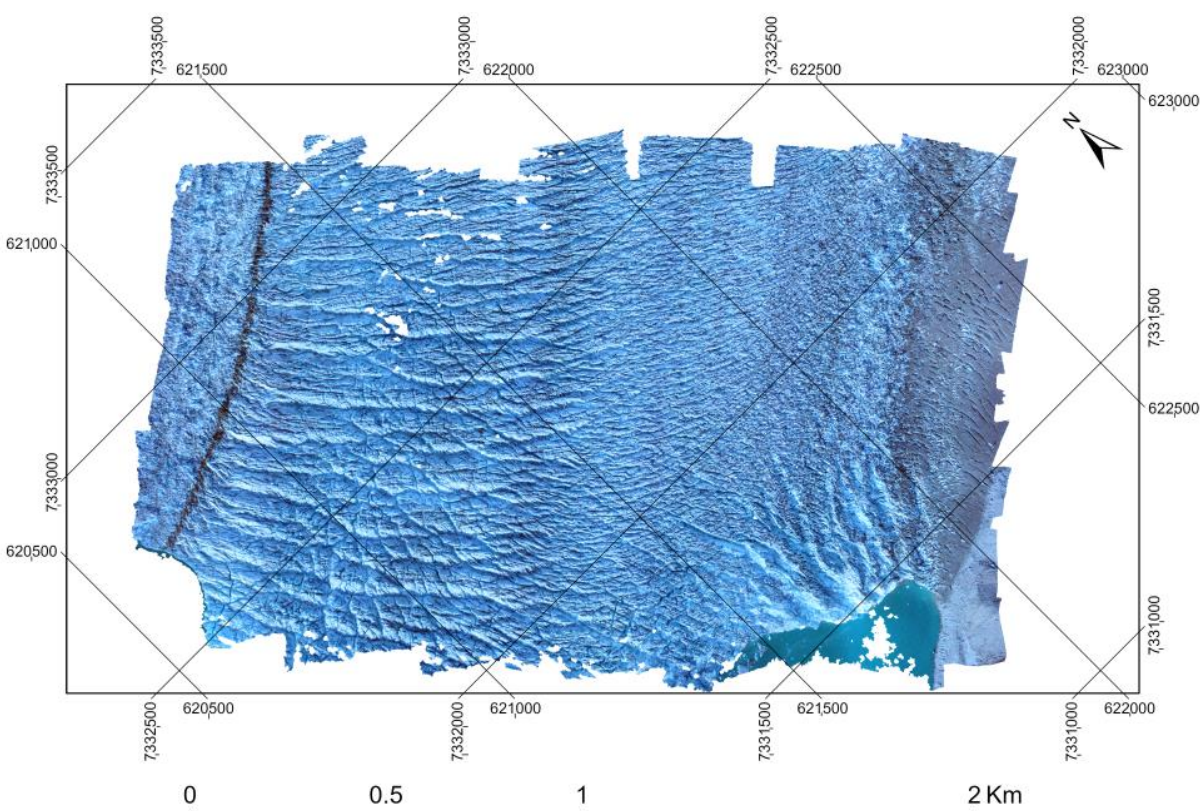

Figure 10. Flight no.1 and flight no.2 (orthophoto in near infrared range). On the second orthophoto there are shadows, which make the picture more plastic. 


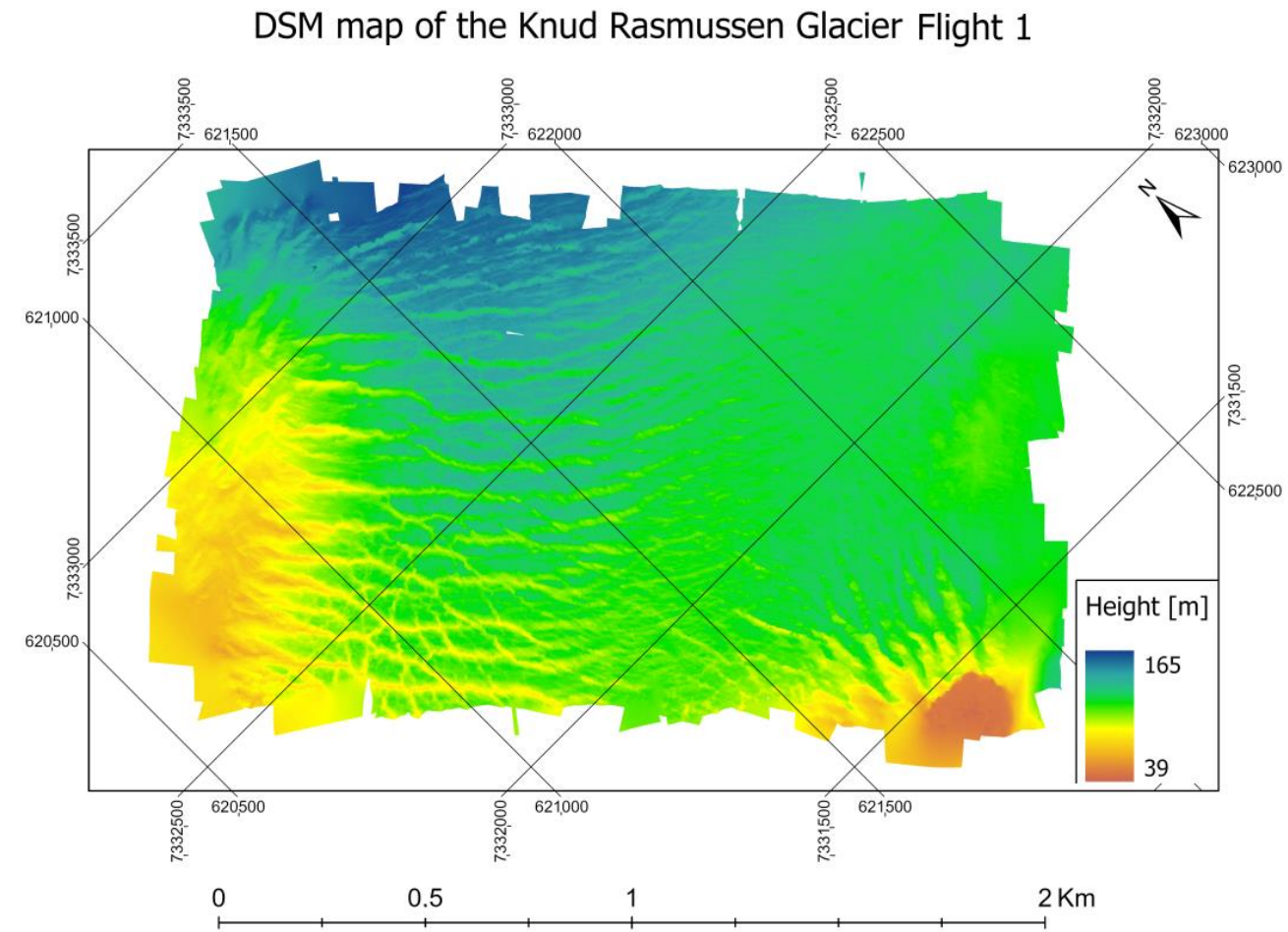

DSM map of the Knud Rasmussen Glacier Flight 2

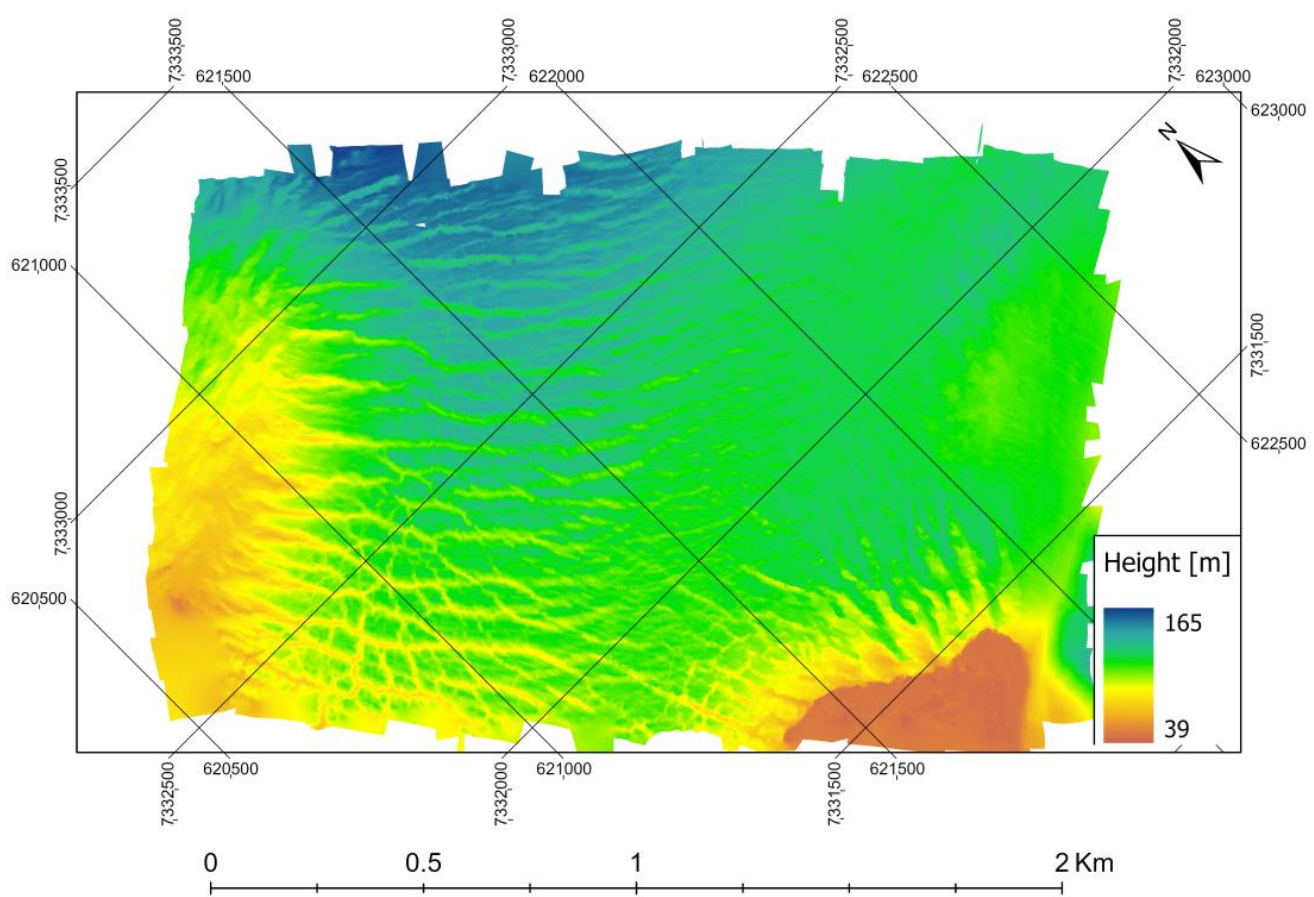

Figure 11. Flight no.1 and no.2—-digital surface model (DSM).

The absolute position error of point clouds and orthophotos is given by the onboard GNSS device, which was in this case a common GNSS working with code mode with a precision of 3-5 $\mathrm{m}$. For this reason it was not possible to use originally geocoded data for computing of the glacier movement, which was expected in m only. However, the internal accuracy is much higher, and in this case reaches $20 \mathrm{~cm}$ according to the pixel size. The precision of points in the point cloud derived from the photographs depends on filtering 
procedures. Points computed from only two photos were deleted, such as points with errors more than three pixels on images.

\subsubsection{Joining of Both Point Clouds}

Accurately referencing both point clouds from individual flights was not typical, because no terrestrial geodetic measurement was made. There were no precisely measured control points (GCP); it would be impossible to place and measure them on the glacier. GNSS equipment on the drone has an accuracy of 3-5 m, which is insufficient for precise georeferencing of projection centers by taking of photos and for georeferencing of computed points in point cloud derived from these photos. The assumption of movement in a few hours was one to several $\mathrm{m}$ maximally. The RTK system was unavailable and it would not work here due to the short measurement time and conditions, and no reference station was at our disposal either. The precise joining of both point clouds from the two overflights to one system was made as follows:

The first model was defined as a reference and the second was transformed into it. However, a problem occurred with the joining of the second point cloud with the control points detected at the edge of the model only.

The software performs the joining of both point clouds using the control points. These control points were found on the first model, but only on edges of the model, in a stone moraine. These found points were relatively stable and were used as fixed points. In the middle of the glacier, considerable movement was expected, and it was not possible to define high-quality fixed control points; due to this, the calculation using the new bundle adjustment process deformed the second model by correcting the elements of external orientation. The model curled, then a deformation occurred, and it reached more than two $\mathrm{m}$ (Figure 12).
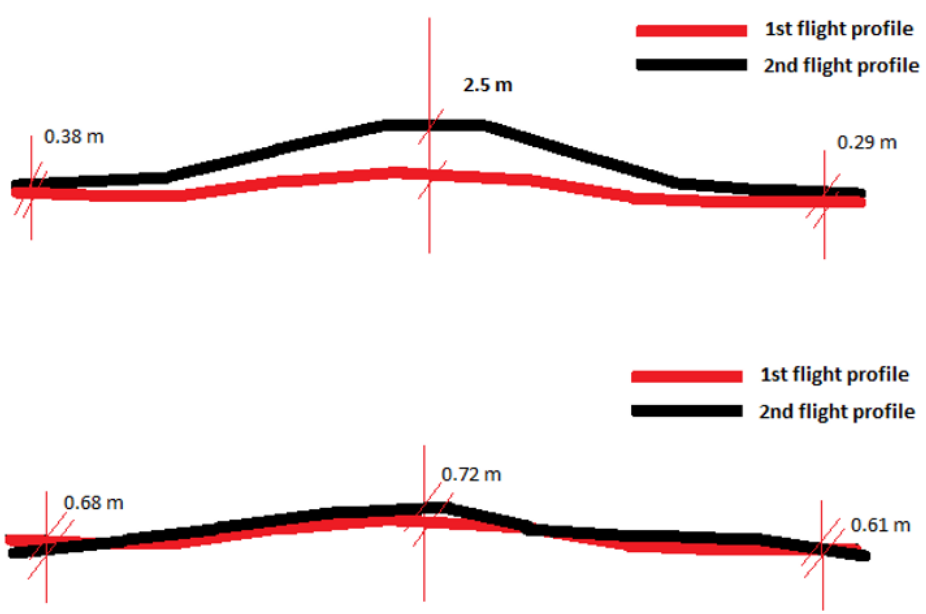

Figure 12. Schematic deformation of both models after joining the point clouds with control points, found at the edge of the model in a stone moraine (it should be stable). By joining both point clouds, the second was deformed in the middle due to the recalculation of the bundle adjustment (e.g., the internal and external parameters can be changed). For this reason, we used both point clouds, as they were processed separately, and the joining was made using similarity transformation only in external software.

It was necessary to use a different procedure. Models (point clouds) cannot be joined only at fixed control points at the edges of the model, because then generally an unknown deformation occurs in the middle of the model. Both point clouds were calculated separately, and the second point cloud was joined only by a similarity transformation (shifts, three rotations, scaling) using six control points directly in CloudCompare software and university software Tran independently together [15]. It finally gave usable results with an RMS (root mean square) of $0.67 \mathrm{~m}, 0.69 \mathrm{~m}$, respectively. A total of eight potential control 
points were found, and only six were used, which was an error less than twice of mean error (RMS). No exact control points measured with a precise GNSS device were at our disposal.

A similarity transformation in 3D was used (Equation (1)):

$$
\left(\begin{array}{l}
X \\
Y \\
Z
\end{array}\right)=\left(\begin{array}{l}
X_{0} \\
Y_{0} \\
Z_{0}
\end{array}\right)+m \cdot R \cdot\left(\begin{array}{l}
x \\
y \\
z
\end{array}\right)
$$

where $(X, Y, Z)$ are the final coordinates in the system of first model, $\left(X_{0}, Y_{0}, Z_{0}\right)$ are the shifts, $m$ is the scale and $(x, y, z)$ are the coordinates in the second model.

The spatial seven-element transformation - the similarity transformation-is given by seven unknowns, three translations, three rotations, and one scaling. It can be possible to use the affine spatial transformation, which similar to the seven-element transformation, but it has nine unknowns, and there are three scale values - a different scale for each axis. To calculate the transformation key, it is necessary to calculate approximate values and proceed with these by iteration. Both types of transformation were calculated, but the difference between them was minimal in our case, only in units of centimeters. However, in the case of incorrectly determined identical points, a problem with the convergence of the calculation occurs. Both types of transformation are programmed in Delphi, originally at the Faculty of Civil Engineering, such as other university software for geodetical using [15].

$m$ is a scalar (similarity transformation) or $M$ is a matrix (affine transformation, Equation (2):

$$
M=\left(\begin{array}{ccc}
m_{x} & 0 & 0 \\
0 & m_{y} & 0 \\
0 & 0 & m_{z}
\end{array}\right)
$$

Finally, this transformation result was done with the RMS $=0.67 \mathrm{~m}$. Many parameters affected the resulting accuracy. The main ones were the pixel size of $10 \mathrm{~cm}$ and the type and structure of the surface, including the possible actual deformation of the glacier over time (Equation (3)). Better results cannot be expected under the current conditions and chosen equipment. It should be noted that the model was created from images taken in a time span of approximately $35 \mathrm{~min}$. Even in this short time, parts of the glacier moved, which affected the result.

$$
T_{\text {trans }}=\left(\begin{array}{cccc}
1.001 & 0 & -0.001 & -85.045 \\
0 & 1.001 & -0.001 & -90.371 \\
0.001 & 0.001 & 1.001 & -0.034 \\
0 & 0 & 0 & 1
\end{array}\right) \text { RMS }=0.667566[\mathrm{~m}]
$$

Equation (3) shows the final RMS for both point clouds joining and the transformation matrix (CloudCompare software).

\subsubsection{Analyzing the Glacier Flow Speed}

CloudCompare software calculates the distance between two similar point clouds in the direction of normals; in this case, the solution cannot be successful due to irregular shifts of the glacier.

Here we do not have two almost identical point clouds, between which we measure the differences in the perpendicular direction to the surfaces, meaning in direction of normals. Here is the original point cloud and a new point cloud, which was created by irregularly differentially moving the first point cloud. Measuring the movement of the flow and its direction is thus much more complicated. It is necessary to define a point in the original point cloud and, according to its unique surroundings, try to find this point in the second shifted point cloud. If we succeed, we have the direction and magnitude of the shift. These parameters will be different for each point. The M3C2 (Model-to-Model Cloud Comparison) distance in a special module in CloudCompare software solves this problem. 
The next part was the analysis of the joined models and the search for real shifts in time as described above. A comparison of changes was performed using the Model-to-Model Cloud Comparison (M3C2) method [16]. This is a method of calculating the distance or discrepancies between two clouds generally, and not in the classical direction of normals. The method calculates distances only for so-called core points, which is the selection of a smaller sample of points from the whole reference point cloud. The points are usually selected based on the minimum distance they must contain. In the first step, the normal vectors for each point are calculated. All points located at the maximum spherical distance (s) specified by the user from the core points are used to calculate the normals. If the clouds contain normal vectors from post processing, these normals can be used.

For each core point, a normal vector is calculated, which is the average of the normals of all points that lie from the core point with the maximum distances. This vector forms the axis of the cylinder. In the next step, a cylinder with a user-defined height $(h)$ and radius $(r)$ is interposed by a cloud. The core point forms the center of this cylinder. The position of a point is calculated as the average of all points that are in this cylinder. A more detailed description of the method can be found in Lague et al. (2013) [17-19], (Figures 13 and 14).

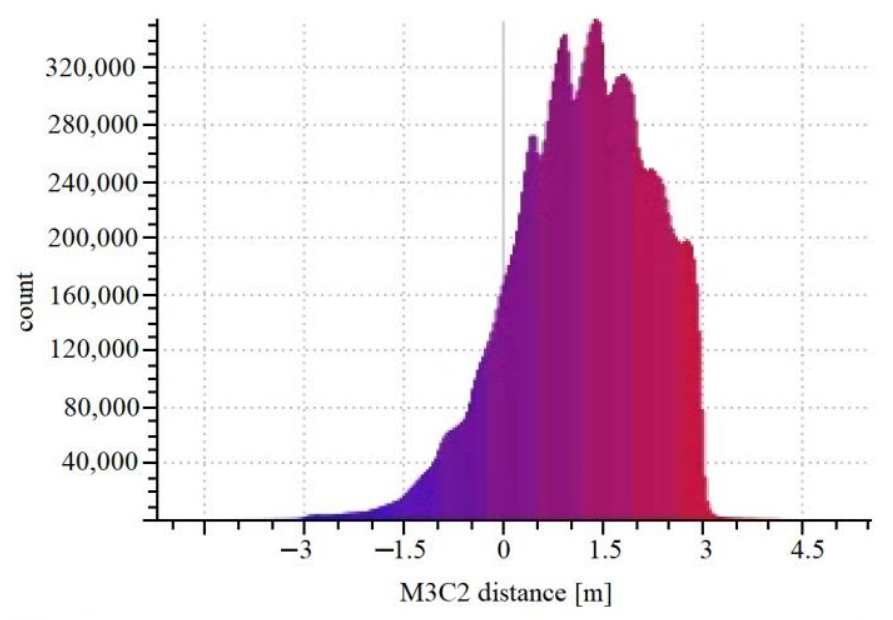

Figure 13. Histogram of the Model-to-Model Cloud Comparison (M3C2) distance. Negative values are errors from the computation occur on the borders only, caused by missing marginal data in both files. These data were filtered out.

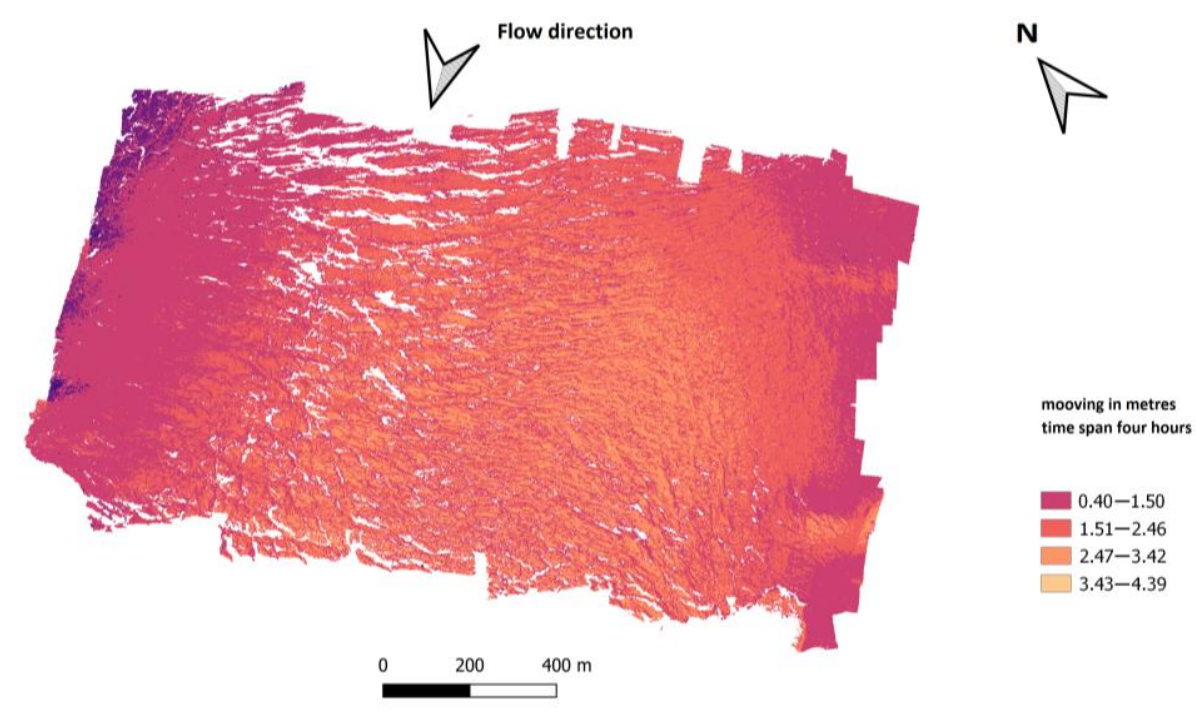

Figure 14. Areas of significant change on the Knud Rasmussen Glacier in the time span of four hours. The values: the flow speed; the purple colored parts on the left are caused by missing data from flight No.1. 
The results of the analysis show that the glacier moves fastest in the middle with the speed of 2-3 $\mathrm{m}$ in a time span of four hours. The histogram (Figure 13) shows that the mean speed of the glacier is one meter per four hours. From the results it can be concluded that with an error of $0.67 \mathrm{~m}$ the glacier Knud Rasmussen moves at an average speed of around six $\mathrm{m}$ per day. The fastest parts can have a speed of 12-15 $\mathrm{m}$ per day, while the border parts move practically by this method immeasurably in the short time span (Figure 14). This agrees with other studies [10,20-22].

\subsection{Processing of Historical Image Data}

\subsubsection{Historical Aerial Images from the 1930s}

The set consists of several oblique aerial images in the form of scanned photocopies. The original images were taken by the Fairchild F-8 photogrammetric camera, which was released in 1930. Original images from the Fairchild F-8 camera were taken on $5^{\prime \prime} \times 7$ " film. The focal length was $240 \mathrm{~mm}\left(12^{\prime \prime}\right)$. We found only this information about the photos. The fiducial marks were very difficult to find, and the frame data were unusable. It was uncertain whether the photographs were complete in the original format. Fortunately, the center of the image was highlighted by a puncture and a mark in the photographs. All scanned paper photocopies had to be transformed into detected centers, fitted and cropped according to poorly visible fiducial marks to the same format. Projective transformation was used, which got the best results (Figure 15).

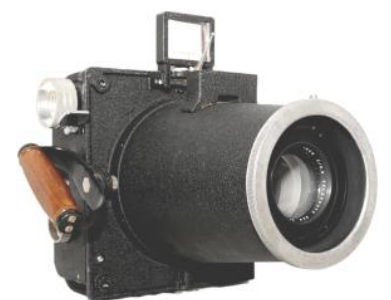

(a)

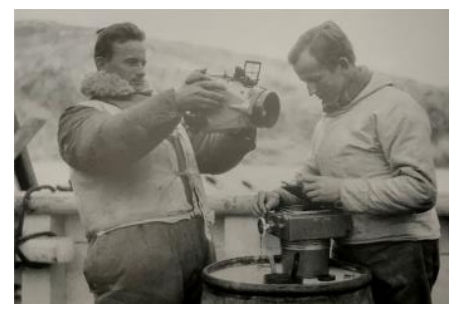

(b)

Figure 15. (a) The Fairchild F-8 camera, (b) a historical photo with the pilot and photographer in the book. The photographer holding a Fairchild F-8 camera [7].

Only eight historical images were selected, from which a project was created to process image information into a 3D model. It was necessary to define at least the basic parameters instead of the elements of internal orientation. A focal length of $240 \mathrm{~mm}$ was used, and the pixel size $(14.2 \mu \mathrm{m})$ was derived from the size of the scanned photographs in pixels and lines based on the original image size of $5^{\prime \prime} \times 5^{\prime \prime}$. The additional part of the film was used for frame information, such as time and photo number. Metashape software was used. Automatic processing was not possible due to the low quality of scanned paper photocopies and the unknown internal and external parameters of the chosen photogrammetrical images. It was necessary to find suitable tie points manually; in the end, 25 tie points were used for a correct calculation. A sparse cloud was calculated, and the points were filtered using a "gradual selection" procedure, which filtered out points with error of bigger than ten pixels. This parameter was set empirically so that approximately $30 \%$ of all points were deleted from the processing. The camera parameters were recalculated until stable results were obtained. Some pictures did not have a regular photogrammetric overlap; they were taken by hand and it was almost always a pair of similar pictures. From the photo-flight sequence of the Knud Rasmussen Glacier, all images were finally successfully processed. An illustrative model of the historical status was calculated (Figures 16-19). 


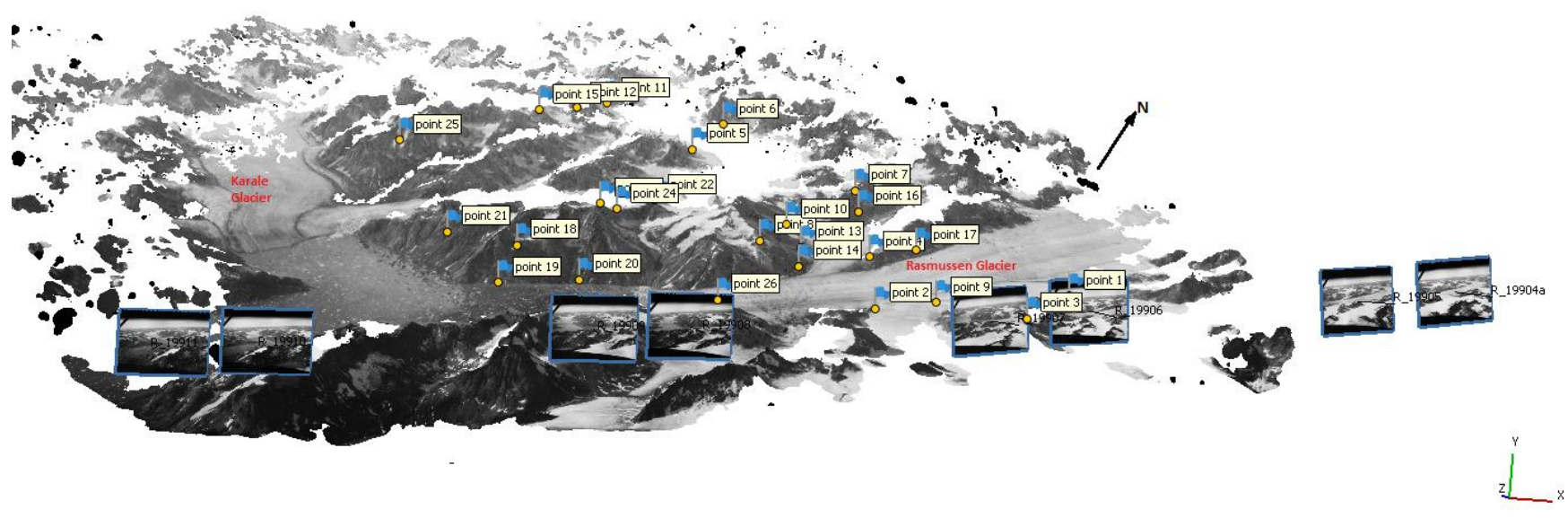

Figure 16. The created three-dimensional (3D) model of Karale (left) and Knud Rasmussen glacier mouths (right) with tie points and photo positions; 1.23 million faces.

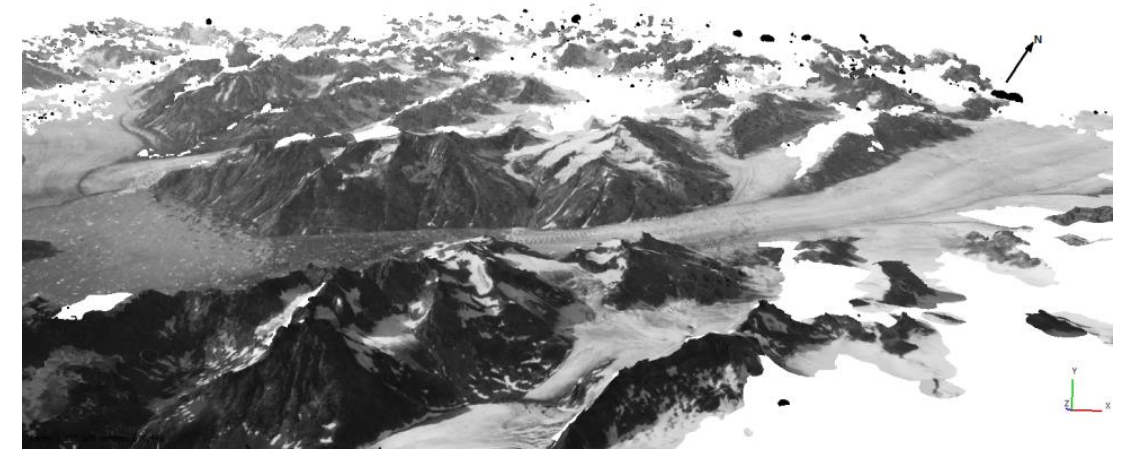

Figure 17. A detail of the 3D model—the Knud Rasmussen Glacier in the 1930s.

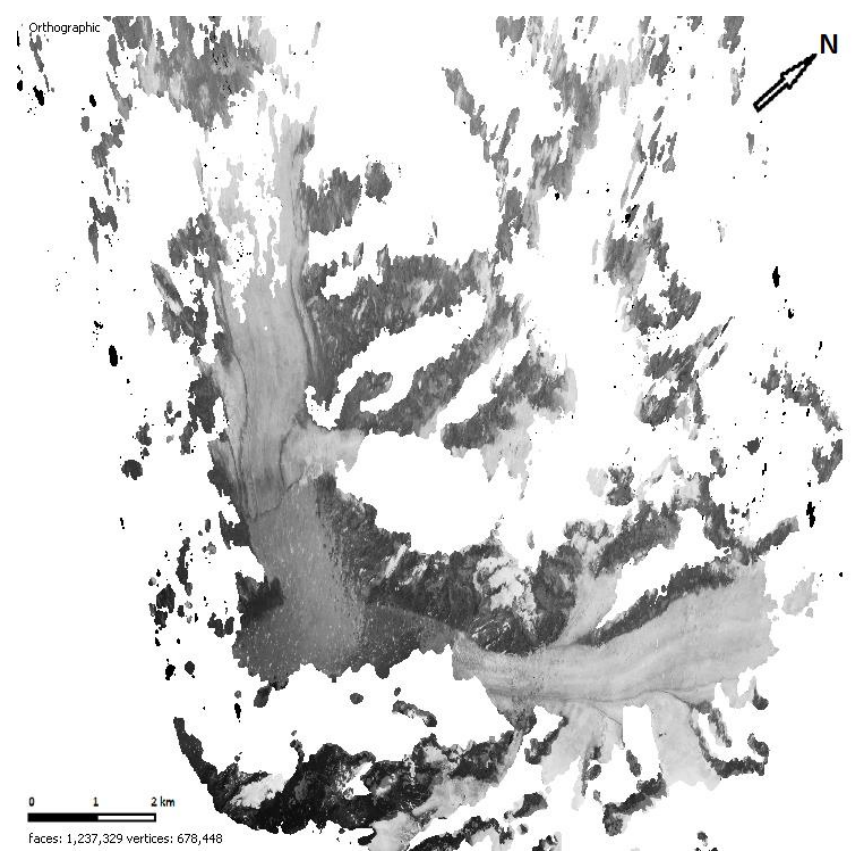

Figure 18. An orthographic view of the 3D model shows glacier mouths; it can be joined with satellite and drone images. Unfortunately, the images were taken at a low angle oblique, which caused a considerable amount of hidden parts due to the perspective (white areas). 


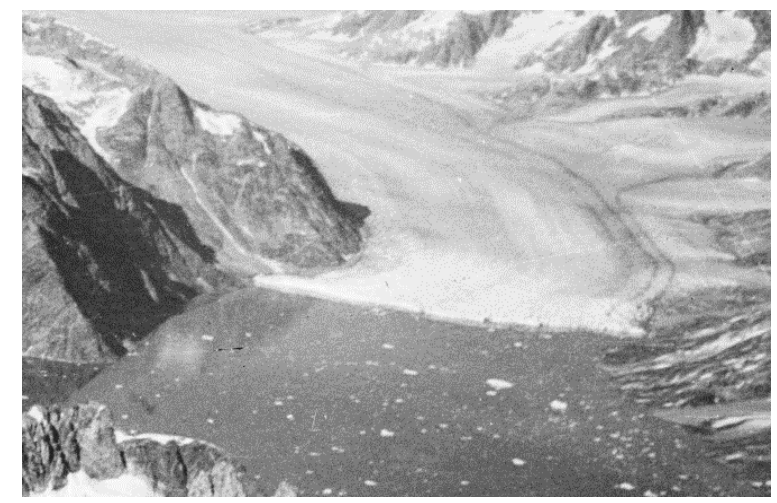

Figure 19. The Knud Rasmussen Glacier in a historical photo (detail); unfortunately, from this photo, it is not possible to get $3 \mathrm{D}$ information (only the glacier delimitation).

An interesting result is the fact that the face of the Knud Rasmussen Glacier changed little over time compared to the other, dramatically receding glaciers, such as Jakobshaven Glacier on the west coast [20,21], including right next to the mouth of the Karale Glacier (the glacier on the left part of the model).

\subsubsection{Archive Landsat Satellite Data}

Google Earth provides previews of Landsat satellite data from 1984 to 2016 (Figure 20) for the Karale and Knud Rasmussen Glaciers. The data were always taken on the same day (directly on the last day of the year, 31 December), which is an advantage for comparison. In ArcGIS, all of the images were compared (Figure 20). It can be seen from the series of images that major changes to the front of the Knud Rasmussen Glacier did not occur until after 2011. The Karale Glacier began to recede as early as 1990.

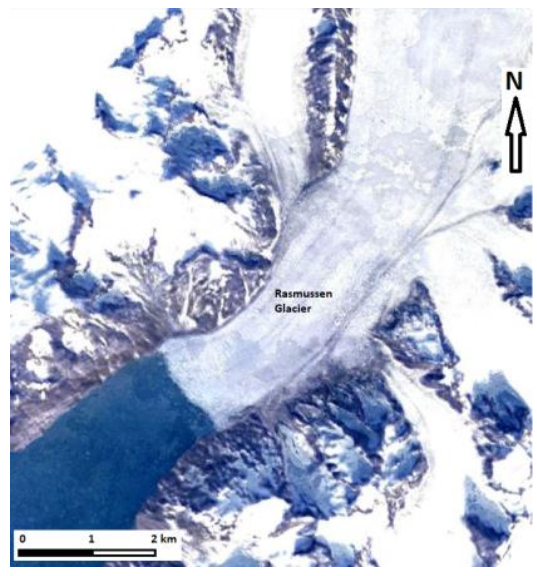

(a)

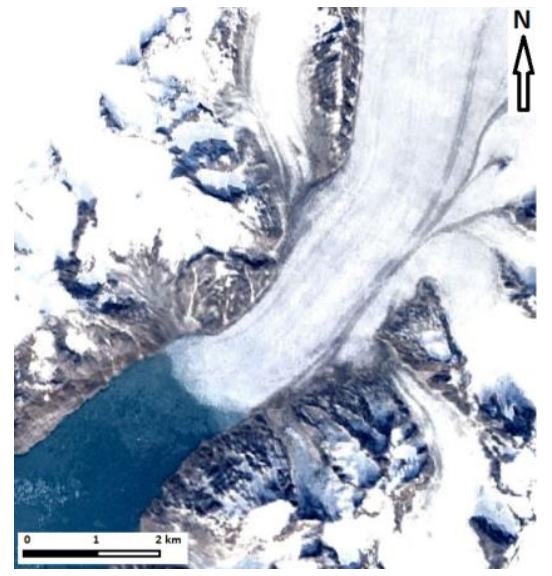

(b)

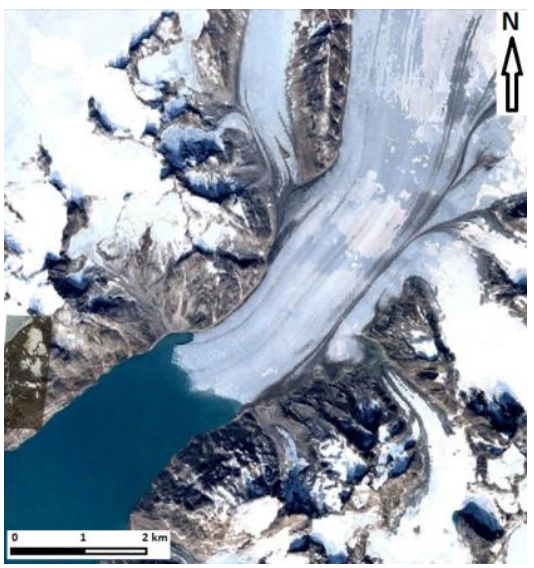

(c)

Figure 20. Landsat data from Google Earth (a) from 1984, (b) from 2002, (c) from 2016.

\subsubsection{Archive Sentinel Satellite Data}

As a new type of free satellite data, the Copernicus system was used, especially the Sentinel 2a satellite (Figure 21). Unfortunately, in the archive, only data from last two year are on-line. Older data must be ordered. Most of the satellite scenes are cloudy and cannot be used for this work, the images taken during summertime can be used without processing problems, other can be affected by the shadows, which are in the Greenland due to short day time very long (Figure 21b). We processed scenes from summertime and wintertime between 2019 and 2020 for prolonging of our study and research of usability of different image data. For comparison with other image data, only the one multispectral 
channel (Red) with a pixel size of $10 \mathrm{~m}$ was used. These images were used for delimitation of the Knud Rasmussen Glacier front. As it is visible on (Figure 21a,b), the glacier lost a front part after summertime in 2020.

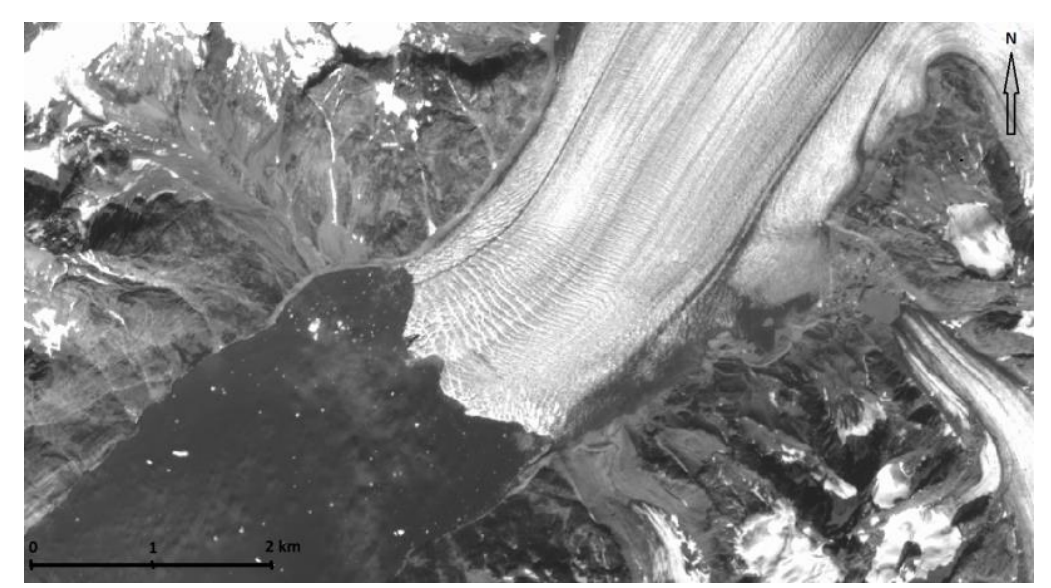

(a)

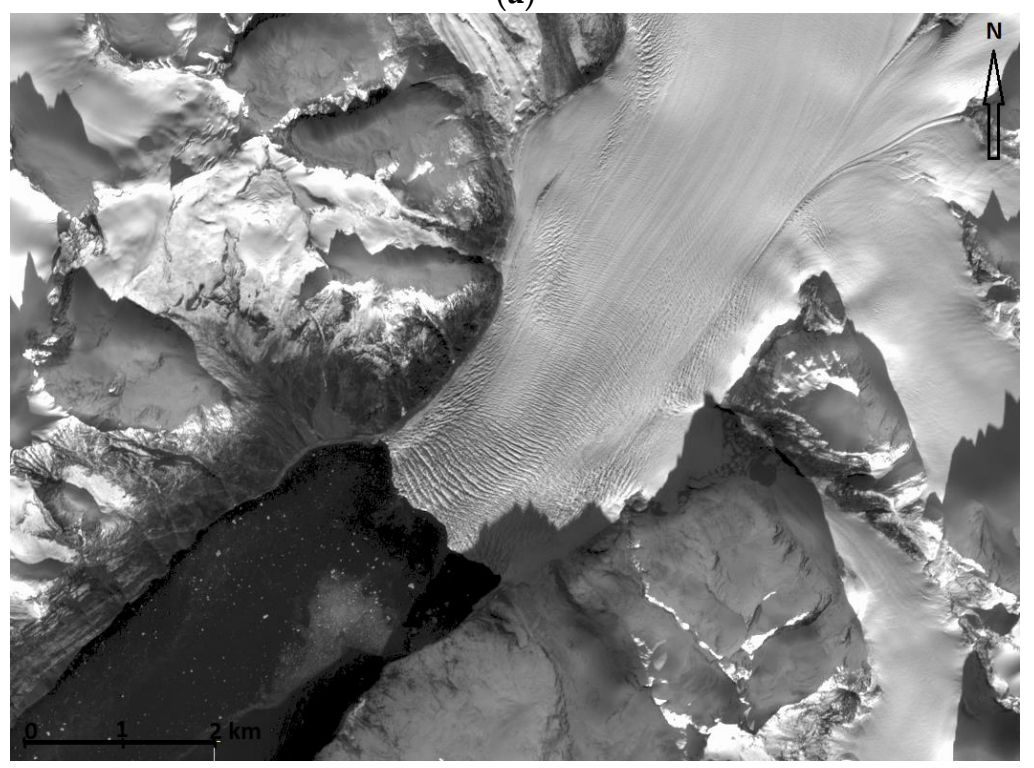

(b)

Figure 21. Sentinel 2a data; (a) 31 July 2020, (b) 9 October 2020, lower part of the glacier is affected by hill shadows.

\subsection{The Knud Rasmussen Glacier Time Changes}

All collected image data were processed in the ArcGIS software to the final map, which shows the glacier extent changes. In the 1930s, the condition of the glacier was almost the same as in the early new millennium until 2011. This is quite clearly evident from the georeferenced orthophoto from the 1930s compared with the Landsat data from 1984 to 2016. In 1932, the north-eastern part of the glacier front was located at a similar position as it was from 2011. The face of the glacier from 1932, based on the processing of the historical images, was behind the position from 1984. However, while we do not know exactly when the flight was made, we do know that it was very likely in the summer. The question is what the front of the glacier looked like in winter in the 1930s. Similarly, the data from 2019 to 2020 are from a summer that was warm (Figures 22 and 23). Landsat satellite dates are always from winter; Sentinel 2a data are from summer and autumn. 


\section{Time Changes of the Knud Rasmussen Glacier}

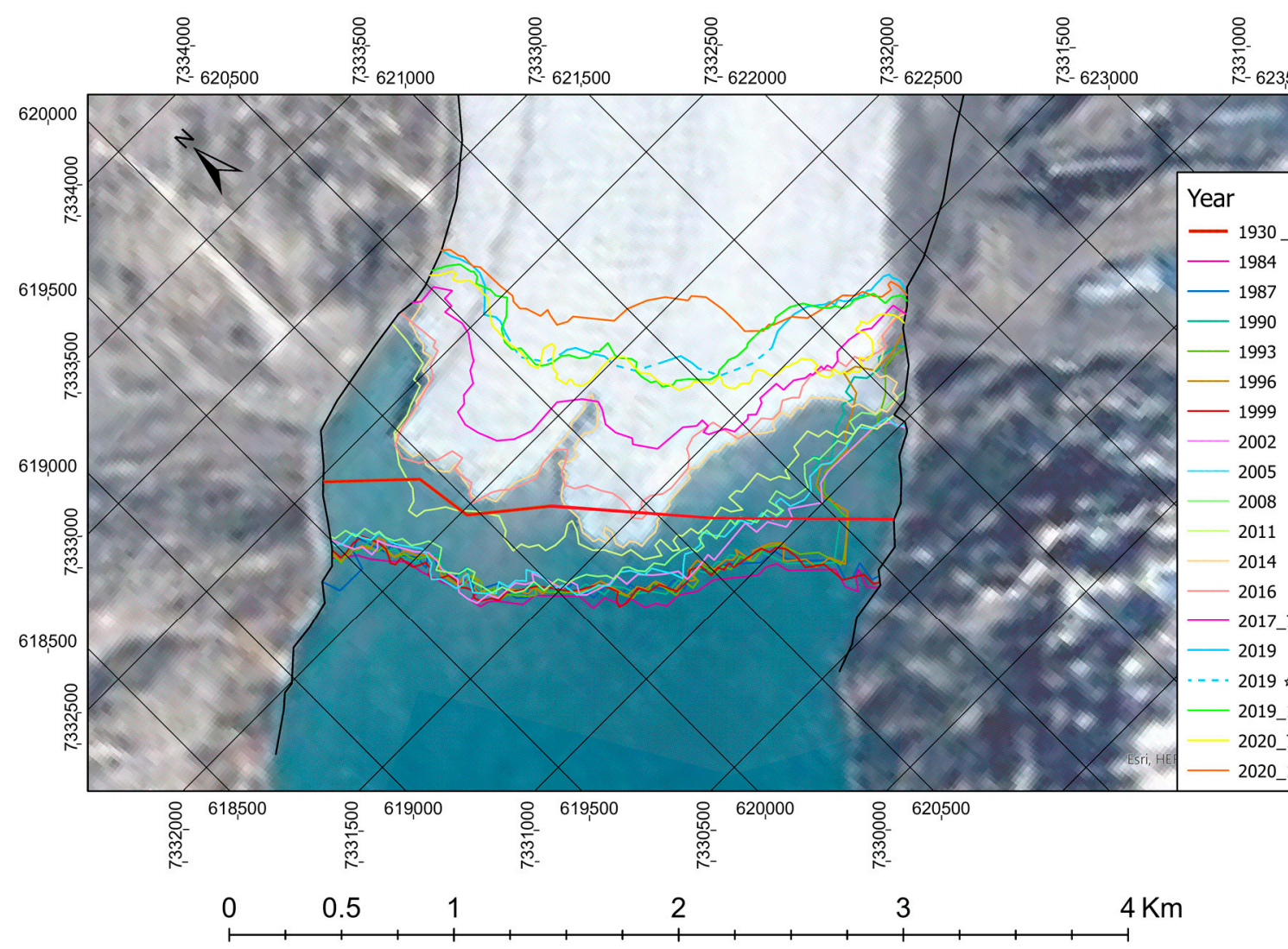

Figure 22. A final interpretation of the Knud Rasmussen Glacier changes between 1932 and 2020 (2019* are data from the eBee drone, some parts were missing).

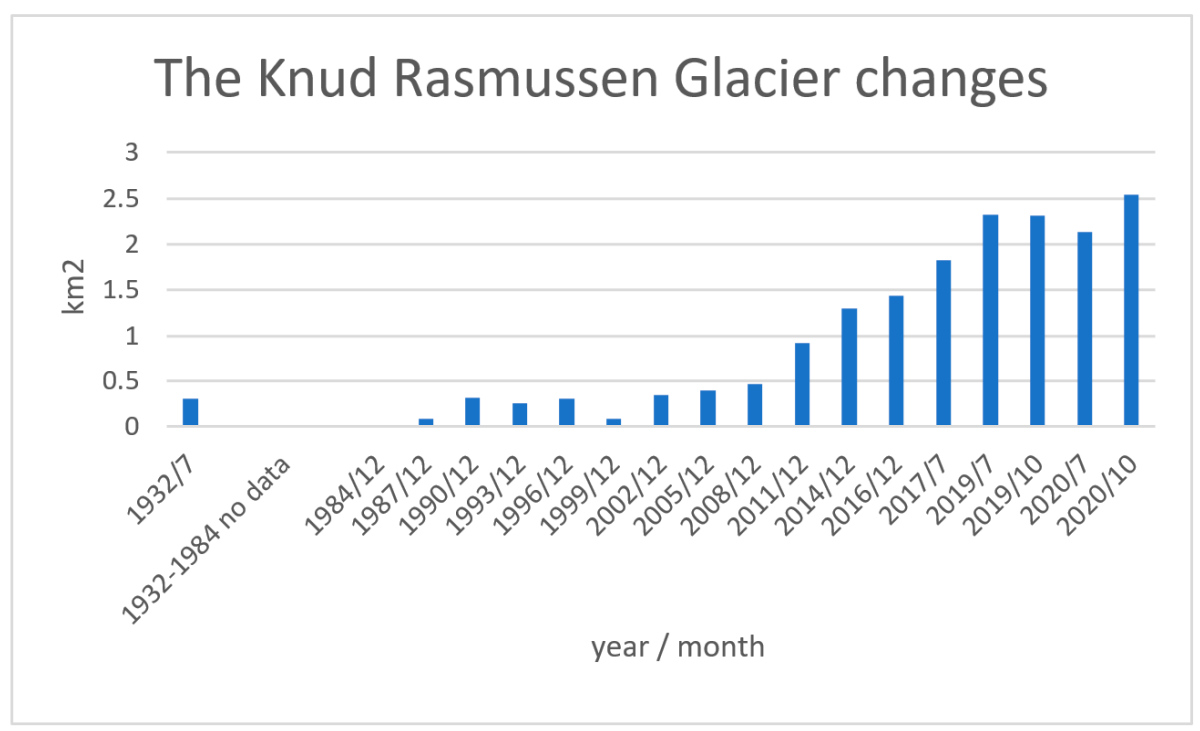

Figure 23. The Knud Rasmussen Glacier area changes between 1932 and 2020; the basic state was the year 1984 (i.e., the state "zero"). Between 1932 and 1984, we do not have data about the glacier status.

\section{Discussion and Conclusions}

The first part of this research looked at the possibility of monitoring the flow rate and its distribution of the face of the Knud Rasmussen Glacier in eastern Greenland using RPAS based on point cloud time changes detected from two overflights. According to the 
available results, the most significant changes occur in the middle part of the studied glacier. For computing the displacement of both point clouds derived from photo-sets in different time, the M3C2 distance from CloudCompare software was used. The displacement values histogram shows that the changes rarely exceed three $\mathrm{m}$. A typical movement of the middle part of this glacier can be from 2 to $3 \mathrm{~m}$ in $4 \mathrm{~h}$, but a mean speed based on the local histogram maximum is only $1 \mathrm{~m}$ in a time span of $4 \mathrm{~h}$. There is a possible error of up to RMS $67 \mathrm{~cm}$, given the inaccuracy of joining both point clouds. In conclusion, the use of a drone for monitoring the speed of the movement and its distribution of the glacier is possible even after a relatively short time span.

The fastest running ones have a speed in the middle of up to tens of $\mathrm{m}$ per day, such as the Eqi Glacier or the Jakobshavn Glacier in west Greenland. In the case of the Knud Rasmussen Glacier, the flow rate in the middle nearby the glacier face is considerable and can reach a value of around $12-15 \mathrm{~m}$ per day at most; however, this is only an extrapolation, but it correlates with the measurement on other glaciers. Here, problems were found: only a short time span was used, only one measurement in the summertime was carried out, the parameters of the flight were not ideal due to the local conditions and lack of time. Any precisely measured control points were used. The problems with the precision and time of flight can be nowadays solved with a modern eBee RTK with a base station and with better quality batteries, and with more time for these experiments.

The second goal of our research was aimed at an analysis of using and joining different image data for the monitoring of this glacier, mainly new processing of old historical aerial oblique images from the 1930s. From the historical images, we can deduce that the Knud Rasmussen Glacier receded inland mainly after 2011. This glacier retreat inland is not so progressive as that of other glaciers, which have receded $\mathrm{km}$ inland due to climate change. An analysis of historical aerial images, Landsat and Sentinel satellite images, and new drone orthophoto shows that the front of the Knud Rasmussen Glacier was in practically the same place until 2011. Only later did the glacier begin to recede. Unfortunately, data from 1933 to 1983 is unreachable or missing for us. We could not find out what the situation was in the fifty missing years. The new drone images, such as Sentinel data from 2019 to 2020 , show the accelerated retreat of the glacier front in recent years. However, the newest (2019-2020) and the oldest (1932-1933) image data were obtained in the summer, satellite data from Landsat were always acquired on the last day of the year, and the cloud-free data from the Sentinel satellite were taken partially in summertime and partially in the autumn. Thus, a seasonal change is possible in this summer data, and the data have less significance with regard to long-term development. Even so, it is certain that the melting of the glacier is happening, and it is accelerating.

Author Contributions: Conceptualization, K.P.; methodology, K.P. and K.P.J; technical advisory and supervision, K.P. and J.Š.; data processing, K.P., K.P.J., and J.Š.; investigation, K.P.; writing—original draft preparation, K.P.; writing-review and editing, K.P.J. and J.Š.; visualization, K.P., K.P.J., and J.Š.; project administration, K.P. All authors have read and agreed to the published version of the manuscript.

Funding: This research was funded by the Czech Technical University in Prague Grant number SGS20/053/OHK1/1T/11 and the APC was funded by the Czech Technical University in Prague, FCE, department of Geomatics.

Institutional Review Board Statement: No applicable.

Informed Consent Statement: No applicable.

Data Availability Statement: The used data were collected during the expedition and from open sources, as written (Landsat, museum data, Copernicus).

Acknowledgments: We would like to thank Arved Fuchs and crew member Dagmar Aaen for an incredible experience and perfect service, to Robert Peroni (Tasiilaq, Greenland) for friendly welcome and valuable advice, and to Anders Anker Bjørk (University of Copenhagen) for the photographs provided and the immediate and friendly response. 
Conflicts of Interest: The authors declare no conflict of interest. The funders had no role in the design of the study; in the collection, analyses, or interpretation of data; in the writing of the manuscript, or in the decision to publish the results.

\section{References}

1. Greenland Rapidly Rising as Ice Melt Continues. 2020. Available online: http://www.miami.edu/index.php/news/releases/ greenland_rapidly_rising_as_ice_melt_continues / (accessed on 5 October 2020).

2. Encyclopædia Britannica. 1999 Multimedia Edition. Available online: https://www.britannica.com/place/Greenland (accessed on 28 October 2020).

3. Stocker, T.F.; Qin, D.; Plattner, G.K.; Tignor, M.; Allen, S.K.; Boschung, J.; Nauels, A.; Xia, Y.; Bex, V.; Midgley, P.M.; et al. Climate Change 2013-The Physical Science Basis: Working Group I Contribution to the Fifth Assessment Report of the Intergovernmental Panel on Climate Change; Cambridge University Press: Cambridge, UK, 2014. [CrossRef]

4. Slater, T.; Hogg, A.E.; Mottram, R. Ice-sheet losses track high-end sea-level rise projections. Nat. Clim. Chang. 2020, 10, 879-881. [CrossRef]

5. Mouginot, J.; Rignot, E.; Bjørk, A.A.; Van den Broeke, M.; Millan, R.; Morlighem, M.; Noël, B.; Scheuchl, B.; Wood, M. Forty-six years of Greenland Ice Sheet mass balance from 1972 to 2018. Proc. Natl. Acad. Sci. USA 2019, 116, 9239-9244. [CrossRef]

6. Sasgen, I.; Wouters, B.; Gardner, A.S.; King, M.D.; Tedesco, M.; Landerer, F.W.; Dahle, C.; Save, H.; Fettweis, X. Return to rapid ice loss in Greenland and record loss in 2019 detected by the GRACE-FO satellites. Commun. Earth Environ. 2020, 1, 1-8. [CrossRef]

7. Bjørk, A.A.; Kjær, K.H.; Larsen, N.K.; Kjeldsen, K.K.; Khan, S.A.; Funder, S.V.; Korsgaard, N.J. The Greenland Ice Sheet-80 Years of Climate Change Seen from the Air; Natural History Museum of Denmark, Faculty of Science, University of Copenhagen: Copenhagen, Denmark, 2014; 180p, ISBN 978-87-87519-46-5.

8. $\quad$ Bjørk, A.A.; Kjær, K.H.; Korsgaard, N.J.; Khan, S.A.; Kjeldsen, K.K.; Andresen, C.S.; Box, J.E.; Larsen, N.K.; Funder, S. An aerial view of 80 years of climate-related glacier fluctuations in southeast Greenland. Nat. Geosci. 2012, 5, 427-432. [CrossRef]

9. Näcke, L. Vergleich Kinematischer GNSS-Daten aus Ostgrönland (Comparison of Kinematic GNSS Data from East Greenland). Bachelor's Thesis, Brandenburgische Technische Universität Cottbus-Senftenberg, Cottbus, Germany, 2020.

10. Pavelka, K.; Šedina, J.; Matoušková, E.; Hlaváčová, I.; Korth, W. Examples of different techniques for glaciers motion monitoring using InSAR and RPAS. Eur. J. Remote Sens. 2019, 52, 219-232. [CrossRef]

11. Bash, E.A.; Moorman, B.J.; Gunther, A. Detecting Short-Term Surface Melt on an Arctic Glacier Using UAV Surveys. Remote Sens. 2018, 10, 1547. [CrossRef]

12. Zwally, J.; Abdalati, W.; Herring, T.; Larson, K.; Saba, J.; Steffen, K. Surface Melt-Induced Acceleration of Greenland Ice-Sheet Flow. Science 2002, 297, 218-222. [CrossRef] [PubMed]

13. Šedina, J.; Housarová, E.; Raeva, P. Using RPAS for the detection of archaeological objects using multispectral and thermal imaging. Eur. J. Remote Sens. 2019, 52 (Suppl. 1), 182-191. [CrossRef]

14. Korth, W.; Hoffman, U.; Hitziger, T.; Küchenmeister, T.; Pawelka, K. Klimabedingte Veränderungen des Inlandeises im südlichen Grönland. In 19. Internationale Geodätische Woche Obergurgl 2017; Herbert Wichmann Verlag: Berlin, Germany, 2017; ISBN 978-3-87907-624-6.

15. Štroner, M.; Pavelka, K. Linear spatial transformation. Geodetický a Kartografický Obzor 2001, 47, $233-235$.

16. M3C2 (Plugin). CloudCompare. Available online: https://www.cloudcompare.org/doc/wiki/index.php?title=M3C2 (accessed on 10 October 2020).

17. Lague, D.; Brodu, N.; Leroux, J. Accurate 3D comparison of complex topography with terrestrial laser scanner: Application to the Rangitikei canyon (N-Z). ISPRS J. Photogramm. Remote Sens. 2013, 82, 10-26. [CrossRef]

18. Barnhart, T.B.; Crosby, B.T. Comparing Two Methods of Surface Change Detection on an Evolving Thermokarst Using HighTemporal-Frequency Terrestrial Laser Scanning, Selawik River, Alaska. Remote Sens. 2013, 5, 2813-2837. [CrossRef]

19. DiFrancesco, P.-M.; Bonneau, D.; Hutchinson, D.J. The Implications of M3C2 Projection Diameter on 3D Semi-Automated Rockfall Extraction from Sequential Terrestrial Laser Scanning Point Clouds. Remote Sens. 2020, 12, 1885. [CrossRef]

20. Gervaix, F. UAV Mapping of a Greenland Glacier. GIM J. 2018. Available online: https:/ /www.gim-international.com/content/ article/uav-mapping-of-a-greenland-glacier (accessed on 28 October 2020).

21. Simonsen, S.B.; Sørensen, L.S. Implications of changing scattering properties on Greenland ice sheet volume change from Cryosat-2 altimetry. Remote Sens. Environ. 2017, 190, 207-216. [CrossRef]

22. Sandberg Sørensen, L.; Simonsen, S.B.; Forsberg, R.; Khvorostovsky, K.; Meister, R.; Engdahl, M.E. 25 years of elevation changes of the Greenland Ice Sheet from ERS, Envisat, and CryoSat-2 radar altimetry. Earth Planet. Sci. Lett. 2018, 495, 234-241. [CrossRef] 